\title{
ANTI-EPILEPTIC DRUG INTAKE ADHERENCE
}

\author{
THE VALUE OF THE BLOOD DRUG LEVEL \\ MEASUREMENT AND THE CLINICAL APPROACH
}

\author{
MARLEIDE DA MOTA GOMES*, HEBER DE SOUZA MAIA FILHO**, \\ ROSÂNGELA APARECIDA MARTINS NOÉ***
}

\begin{abstract}
It was evaluated the patient antiepileptic drug (AED) intake adherence in a pilot cross-sectional study carried out at a neurologic out-patient clinic of a university hospital. Ninety-three AED blood concentration (phenobarbital, phenytoin, carbamazepine) were analyzed from 24 patients. The variability of the AED blood level was measured (in the steady state period by means of the variation coefficient) and compared with the selfreported antiepileptic medication non-adherence, AED blood level according to the range (therapeutic or not), and the seizure control. It was not observed any strong correlation between the higher value of variability and the other three parameters of no adherence. The highest correlation was with the blood drug level (therapeutic or not). The evaluation of blood drug measurement alone, except in cases of extreme low adherence and variability of drug intake, is not enough for the recognition of incorrect drug intake, but the clinical markers and the selfreported adherence have to be also considered for this sort of evaluation.
\end{abstract}

KEY WORDS: epilepsy, adherence, therapeutic blood monitoring, antiepileptic drugs.

\section{Aderência à ingestão de medicamentos antiepilépticos: o valor da avaliação dos níveis sanguíneos e a abordagem clínica}

RESUMO - Avaliou-se a aderência à ingesta de drogas antiepilépticas (DAE) em estudo piloto transversal conduzido em ambulatório de hospital neurológico universitário. Noventa e três amostras sanguíneas com concentração de DAE (fenobarbital, fenitoína, carbamazepina) foram analisadas de 24 pacientes. A variabilidade dos níveis sanguíneos das DAE (em estado estável - steady state period, analizada por meio do coeficiente de variação) foi comparada com a auto-referida não aderência à ingesta da DAE, níveis sanguíneos das DAE de acordo com a faixa (terapêutica ou não) e o controle das crises epilépticas. Não foi observada correlação forte entre o maior valor da variabilidade e os outros três parâmetros de aderência, apesar da maior correlação com o nível sanguíneo (terapêutico ou não). A avaliação do nível sérico isolado, exceto em caso de extrema baixa aderência e variabilidade da ingesta das DAE, não é suficiente para o reconhecimento da ingesta inadequada, mas os marcadores clínicos e a auto-aderência referida também têm que ser consideradas para esse tipo de avaliação.

PALAVRAS-CHAVE: epilepsia, aderência, monitorização de níveis sanguíneos, drogas antiepilépticas.

Poor adherence is considered the most important cause for unsuccessful treatment in epilepsy. Consequently, drug intake adherence is a fundamental process in effective therapy, and in clinical practice its measurement has to be done frequently to apply adherence-improving interventions ${ }^{1-8}$.

Epilepsy Program of the Institute of Neurology, Clinical Epidemiology Program - Department of Internal Medicine, University Hospital, Universidade Federal do Rio de Janeiro: *Associate Professor, Medical Doctor; **Medical Doctor; ***Biostatistician. Aceite: 13-agosto-1998.

Dra. Marleide da Mota Gomes - Caixa Postal 68008 - CCS Bloco K Cidade Universitária - 21944-970 Rio de Janeiro RJ - Brasil. 
Efforts to evaluate adherence include clinical judgment, monitoring attendance at scheduled appointments, monitoring achievement of treatment targets, searching for therapeutic results or side effects, pill counts, drug level measurements and interviews ${ }^{3,9,10}$. The patient interview can supply the most useful practical information and can facilitate the identification and addressing of problems and barriers of adequate adherence, and the self reported adherence is the main question for this kind of evaluation ${ }^{3,7}$. Because of some unique characteristics of antiepileptic drugs and protean manifestations of epilepsy, fine titration of dosage regimen on the basis of concentration of the drug in blood was considered important in achieving seizure control with reduction of potential side-effects mainly in the case of phenytoin use because of its non linear kinetics ${ }^{8,11-13}$. There is different necessity of blood antiepileptic drug (AED) concentration, for instance according to the type of epilepsy, higher in the case of partial epilepsy and lower in the generalized, showing how important the evaluation is in each case ${ }^{11}$. There is also a tendency to believe more in the great variability of the blood drug level for the purpose of drug intake adherence evaluation than the level by itself because it can be influenced by several factors ${ }^{14,15}$.

Self-reported adherence is considered by many investigators a good tool but others report that patients tend to overestimate their adherence ${ }^{3,9}$. In this study, it was explored the relationship between the variability of the blood drug levels, and self-reported antiepileptic medication nonadherence, and also AED level for each specified drug.

\section{SUBJECTS AND METHODS}

This study was implemented at the neurology out-patient clinic of a tertiary hospital, but also with secondary health care coverage. The patients were screened from those seen consecutively if they have detailed clinical history and physical examination, as well as routine laboratory, and EEG that is compatible with the diagnosis of epilepsy. Forty-five were selected and the questionnaires were applied and 24 of them had the three blood samples collected because they followed the initial instructions to return for follow-up regarding the collection of the blood samples.

Patients had to fulfill the following stated criteria stated below to be the sample studied: episodes were witnessed by a person who can provide details of this event to a neurologist, and/or characterized by a specific interictal or postictal EEG; patients were more than 11 years of age, and capable of preparing and administering their own medication. Patients were excluded from the study if one or more of the following conditions existed: presence of underlying acute or progressive neurologic disease; concomitant disease with long-term treatment or malignancy; diagnosis of epilepsy not corroborated or not clearly classified in accordance with the International League Against Epilepsy ${ }^{16}$; alcoholism; psychosis; drug addiction; pregnancy, and concomitant chronic disabling motor or mental disease that would impede voluntary or active participation in this study.

There is not a single tool to accurately evaluate patient drug-intake adherence. This is the reason why three measurement methods are applied, although the one considered the "gold-standard" is the blood AED level. Relevant factors of patients are presented. Also, it was explored the relationship between the variables and self-reported antiepileptic medication non-adherence and AED blood level within the therapeutic range for each specified drug. The self-reported non-adherence is based on the following question: "Did you forget or miss any of your medicine last week?".

This study involves different drugs, with different half-lives, and with daily variation. On account of these difficulties, three measurements were made at least one week apart but all at the same time of the day for each patient, considering the intake of the AED at a regular schedule. The blood samples were collected when the blood AED level was more likely to be in a steady-state period. This is related to the half-life of the AED, and the time required to reach the steady-state period after changing in the dosage. They were analyzed using the enzymeimmunoassay method. The variability in the measurement of different blood samples for each patient was obtained by means of the coefficient of variation C.V. $=100 \% \mathrm{x}(\mathrm{s} / \text { mean })^{17}$. C.V. $>20 \%$ was used as the value of high variability for phenytoin and carbamazepine ${ }^{14,15}$, and $35 \%$ for phenobarbital ${ }^{8}$. The therapeutic range for the different drugs were: phenobarbital $10-40 \mathrm{mg} / \mathrm{l}$, phenytoin 10-20 mg/l, carbamazepine 4-12 mg/l.

The tests applied were: exact of Fisher, $\mathrm{X}^{2}$, Student $\mathrm{t}$ test, Mann-Whitney, and contingency coefficient. The significanCE level adopted was 5\%. Epi Info 6 and SAS were used as the statistical packages. 
Table 1. Basic socio-demographic and clinical data: comparison of patients with blood drug level measured at three occasions and the other patients

\begin{tabular}{|c|c|c|c|c|c|}
\hline \multirow{3}{*}{ Age (sd) } & \multicolumn{2}{|c|}{$\mathrm{n}=24$} & \multicolumn{2}{|c|}{$\mathrm{n}=21$} & \multirow{3}{*}{$\begin{array}{c}\mathrm{p} \\
0.9\end{array}$} \\
\hline & \multicolumn{2}{|c|}{$30.4(10.9)$} & \multicolumn{2}{|c|}{$29.9(10.3)$} & \\
\hline & $\mathrm{n}$ & $\%$ & $\mathrm{n}$ & $\%$ & \\
\hline \multicolumn{6}{|l|}{ Gender } \\
\hline male & 12 & 50.0 & 10 & 47.6 & 0.9 \\
\hline female & 12 & 50.0 & 11 & 52.4 & \\
\hline \multicolumn{6}{|l|}{ Years spent at school } \\
\hline illiterate* & - & 0 & 1 & 4.8 & \\
\hline 4 yrs spent at school & 14 & 58.3 & 10 & 47.6 & 0.5 \\
\hline$>4$ yrs spent at school & 10 & 41.7 & 10 & 47.6 & \\
\hline \multicolumn{6}{|l|}{ Seizure frequency } \\
\hline none & 7 & 29.2 & 8 & 38.1 & \\
\hline \multirow[t]{2}{*}{$1-2 /$ year } & 6 & 25.0 & 2 & 9.5 & \\
\hline & & & & & 0.4 \\
\hline$>3$ but not more $1 /$ month & 10 & 41.7 & 8 & 38.1 & \\
\hline$>1 /$ month & 1 & 4.2 & 3 & 14.3 & \\
\hline \multicolumn{6}{|l|}{ Self-reported non-adherence } \\
\hline yes & 8 & 42.1 & 11 & 57.9 & 0.2 \\
\hline no & 16 & 61.5 & 10 & 38.5 & \\
\hline
\end{tabular}

\section{RESULTS}

Our patients have a similar distribution according to gender, and their mean age is 30.4 years old. Education standards shared by most include ability to read and follow their own medical prescriptions. Half of them have a mild expression of the seizure frequency and the other half have a more severe one (Table 1). These data do not statistically differ from the other 21 patients who do not have three blood samples for the AED blood level evaluation, including the self-reported nonadherence.

Tables $2(\mathrm{a}, \mathrm{b}, \mathrm{c})$ present the blood drug levels, their variability in relation to the three blood samples, self-reported reference of no adherence and the severity of the seizures according to their frequency. It was not observed correlation between the higher value of variability and the other three parameters of non-adherence (Table 3).

Table 4 shows the variability of the blood drug level in the same patient using of different AEDs. Patients 25 and 31 revealed greater variability in the use of carbamazepine than with phenobarbital, of longer half-life.

\section{DISCUSSION}

We could not observe a straight relationship among the blood AED level variability, selfreported non-adherence, therapeutic/non-therapeutic AED blood level or seizure non-control. However, we have methodological limitations in our study, because of the small sample size not fitted to the number of studied variables. In consequence, there was low power to detect differences between the two groups studied. In addition, the observation period of the patients and how closely they were followed for the three drug levels may have affected their adherence so that our findings may not reflect usual relationship among the various measures of adherence, but transient relationships created by their increased level of supervision, if they were suspicious of the undeclared purpose of the study. 
Table 2a. Comparison among phenobarbital blood level, self-reported adherence and seizure recurrence for each patient.

\begin{tabular}{lcccccccc}
\hline Case & 1st sample & 2nd sample & 3rd sample & Mean & SD & VC & $\downarrow$ adherence & Seizure* \\
\hline 6 & 23 & 21.7 & 23.9 & 22.9 & 1.1 & 4.8 & - & yes \\
7 & 23.4 & 23.2 & 24.6 & 23.7 & 0.8 & 3.4 & - & yes \\
10 & 22.4 & 19.9 & 24.2 & 22.2 & 2.2 & 9.9 & yes & - \\
11 & $\underline{46.2}$ & $\underline{43.3}$ & $\underline{44.5}$ & $\underline{44.7}$ & 1.5 & 3.3 & - & - \\
15 & 30.2 & 26.9 & 30.9 & 29.3 & 2.1 & 7.2 & yes & yes \\
17 & 28.1 & 31.5 & 33 & 30.9 & 2.5 & 8.1 & - & - \\
20 & $\underline{40.7}$ & $\underline{43.9}$ & $\underline{43.4}$ & $\underline{42.7}$ & 1.7 & 4.0 & - & - \\
25 & 19.9 & 17.4 & 21.2 & 19.5 & 1.9 & 9.7 & - & - \\
28 & 11.7 & 10.6 & 10.8 & 11.0 & 0.6 & 5.5 & - & - \\
31 & 20 & 19.2 & 14.7 & 18.0 & 2.9 & 16.1 & - & yes \\
33 & 17.6 & 23.6 & 25.4 & 22.2 & 4.1 & 18.5 & - & yes \\
36 & 18.8 & 22.9 & 19.6 & 20.4 & 2.2 & 10.8 & yes & - \\
37 & $\underline{6.4}$ & $\underline{8.6}$ & $\underline{7}$ & $\underline{7.3}$ & 1.3 & 17.8 & - & yes \\
38 & 10.4 & 10.3 & $\underline{8.4}$ & $\underline{9.7}$ & 1.1 & 11.3 & - & yes \\
39 & 24.8 & 15.9 & $\underline{7.8}$ & 16.2 & 8.5 & $\underline{52.5}$ & yes & - \\
40 & 29.5 & 30.1 & 31.4 & 30.3 & 1.0 & 3.3 & - & yes \\
42 & $\underline{61}$ & $\underline{60.6}$ & $\underline{47.1}$ & $\underline{56.2}$ & 7.9 & 14.1 & - \\
\hline
\end{tabular}

$\mathrm{SD}$, standard deviation; VC, variation coefficient; $\downarrow$ adherence, forgotten to take the AED; *Seizure not controlled $\geq 3 /$ year.

Table $2 b$. Comparison among phenytoin blood level, self-reported adherence and seizure recurrence for each patient.

\begin{tabular}{lcccccccc}
\hline Case & 1st sample & 2nd sample & 3rd sample & Mean & SD & VC & $\downarrow$ adherence & Seizure* \\
\hline 011 & $\underline{3.4}$ & $\underline{2.8}$ & $\underline{2.9}$ & $\underline{3.0}$ & 0.3 & 10 & - & - \\
024 & 13 & $\underline{20.6}$ & $\underline{21.7}$ & 18.4 & 4.7 & $\underline{25.5}$ & yes & yes \\
038 & $\underline{6.8}$ & $\underline{5.1}$ & $\underline{7.8}$ & $\underline{6.6}$ & 1.4 & $\underline{21.2}$ & - & - \\
\hline
\end{tabular}

$\mathrm{SD}$, standard deviation; VC, variation coefficient; $\downarrow$ adherence, forgotten to take the AED; *Seizure not controlled $\geq 3 /$ year.

Table 2c. Comparison among carbamazepine blood level, self-reported adherence and seizure recurrence for each patient

\begin{tabular}{lcccccccc}
\hline Case & 1st sample & 2nd sample & 3rd sample & Mean & SD & VC & $\downarrow$ adherence & Seizure* \\
\hline 1 & 4.7 & 4.7 & 4.3 & 4.5 & 0.2 & 4.5 & - & yes \\
11 & $\underline{1.8}$ & $\underline{2.5}$ & $\underline{2.3}$ & $\underline{2.2}$ & 0.4 & 18.2 & - & - \\
16 & 10.6 & 10.3 & 10.1 & 10.3 & 0.3 & 2.9 & - & yes \\
22 & $\underline{2.0}$ & $\underline{2.8}$ & $\underline{3.8}$ & $\underline{2.9}$ & 0.9 & $\underline{31.0}$ & - & - \\
25 & $\underline{2.1}$ & $\underline{1.2}$ & $\underline{1.4}$ & $\underline{1.6}$ & 0.5 & $\underline{31.3}$ & - & - \\
30 & 17 & 11.6 & 12.2 & 13.6 & 2.9 & $\underline{21.3}$ & - & - \\
31 & $\underline{2.7}$ & $\underline{3.5}$ & $\underline{1.5}$ & $\underline{2.6}$ & 1.0 & $\underline{38.5}$ & - & yes \\
37 & 7.9 & 7.9 & 9.4 & 8.4 & 0.9 & 10.7 & - & yes \\
41 & $\underline{3.6}$ & 4 & 4 & $\underline{3.9}$ & 0.2 & 5.1 & - & yes \\
42 & 9.5 & 8.6 & 9.2 & 9.1 & 0.5 & 5.5 & - & yes \\
45 & 5.0 & 4.5 & 4.4 & 4.6 & 0.3 & 6.5 & yes & yes \\
\hline
\end{tabular}

$\mathrm{SD}$, standard deviation; VC, variation coefficient; $\downarrow$ adherence, forgotten to take the AED; *Seizure not controlled $\geq 3 /$ year. 
Table 3. Correlation between the great variability of the AED blood level (VC) and three possible markers of non-adherence (self reported non-adherence, AED blood level, seizure not-control) ( $n=31 *$ )

\begin{tabular}{|c|c|c|c|c|c|c|}
\hline & \multicolumn{2}{|c|}{$\mathrm{CV}>20 \% * *$} & \multicolumn{2}{|c|}{$\mathrm{CV}<20 \% * *$} & \multirow[t]{2}{*}{$\mathrm{p}$} & \multirow[t]{2}{*}{$\operatorname{cc}^{* * *}$} \\
\hline & $\mathrm{n}$ & $\%$ & $\mathrm{n}$ & $\%$ & & \\
\hline \multicolumn{7}{|l|}{ self-reported non-adherence } \\
\hline yes & 2 & 25.0 & 6 & 75.0 & 0.6 & 0.03 \\
\hline no & 5 & 21.7 & 18 & 78.3 & & \\
\hline \multicolumn{7}{|l|}{ blood drug level (mean) } \\
\hline non-therapeutic (higher or lower) & 4 & 33.3 & 8 & 66.7 & 0.2 & 0.31 \\
\hline therapeutic & 3 & 15.8 & 16 & 84.2 & & \\
\hline \multicolumn{7}{|l|}{ seizure not controlled ( $\geq 3$ /year) } \\
\hline yes & 3 & 20.0 & 12 & 80.0 & 0.6 & 0.02 \\
\hline no & 3 & 18.8 & 13 & 81.2 & & \\
\hline
\end{tabular}

$* \mathrm{n}=31$ (in 24 patients-use of different AED by some); ** CV> 35\% for phenobarbital; *** contingency coefficient.

Table 4. Differences between drug-levels for different AED in the same patient (special attention for the level considered therapeutic or not, and its variability).

\begin{tabular}{|c|c|c|c|c|c|c|c|c|c|c|c|c|}
\hline \multirow[t]{2}{*}{ Case } & \multicolumn{4}{|c|}{ Phenobarbital } & \multicolumn{4}{|c|}{ Phenytoin } & \multicolumn{4}{|c|}{ Carbamazepine } \\
\hline & $\begin{array}{l}1 \text { st } \\
\text { sample }\end{array}$ & $\begin{array}{l}\text { 2nd } \\
\text { sample }\end{array}$ & $\begin{array}{l}\text { 3rd } \\
\text { sample }\end{array}$ & $\mathrm{VC}$ & $\begin{array}{l}1 \text { st } \\
\text { sample }\end{array}$ & $\begin{array}{l}\text { 2nd } \\
\text { sample }\end{array}$ & $\begin{array}{l}\text { 3rd } \\
\text { sample }\end{array}$ & $\mathrm{VC}$ & $\begin{array}{l}1 \mathrm{st} \\
\text { sample }\end{array}$ & $\begin{array}{l}\text { 2nd } \\
\text { sample }\end{array}$ & $\begin{array}{l}\text { 3rd } \\
\text { sample }\end{array}$ & $\mathrm{VC}$ \\
\hline 11 & $\underline{46.2}$ & $\underline{43.3}$ & $\underline{44.5}$ & 3.3 & 3.4 & 2.8 & 2.9 & 10.0 & $\underline{1.8}$ & $\underline{2.5}$ & $\underline{2.3}$ & 18.2 \\
\hline 25 & 19.9 & 17.4 & 21.2 & 9.7 & - & - & - & - & $\underline{2.1}$ & $\underline{1.2}$ & $\underline{1.4}$ & $\underline{31.3}$ \\
\hline 31 & 20.0 & 19.2 & 14.7 & 16.1 & - & - & - & - & $\underline{2.7}$ & $\underline{3.5}$ & $\underline{1.5}$ & $\underline{38.5}$ \\
\hline 37 & $\underline{6.4}$ & $\underline{8.6}$ & $\underline{7.0}$ & 17.8 & - & - & - & - & 7.9 & 7.9 & 9.4 & 10.7 \\
\hline 38 & 10.4 & 10.3 & 8.4 & 11.3 & $\underline{6.8}$ & $\underline{5.1}$ & $\underline{7.8}$ & $\underline{21.2}$ & - & - & - & - \\
\hline 42 & $\underline{61.0}$ & $\underline{60.6}$ & $\underline{47.1}$ & 14.1 & - & - & - & - & 9.5 & 8.6 & 9.2 & 5.5 \\
\hline
\end{tabular}

Unfortunately, AED blood evaluation alone frequently does not answer with certainty whether the patient is really non compliant (the drug blood level could be related to the provider or the result of drug interaction, individual variation, age or food intake, for instance). Besides, this evaluation is unavailable in some settings, and involves a collection of adequate samples and some delay of the final result. Also, the evaluation is only a "snapshot in time" as Mattson ${ }^{18}$ appropriately qualified it. In this way the blood level usually does not reflect the actual medication-taking behavior, as the same author emphasized. An additional concern is that this procedure does not consider potential determinants of low adherence, but could only express the result. This suggests that relying on these parameters only extremes of low adherence could be detected. The exaggerated variability of blood drug level or the level by itself not compatible with the prescribed dosage could in this way be self explanatory. It is also a simplistic approach to consider adherence as a dichotomous outcome. Probably, it would be more realistic to understand that there is a wide range of adherence, and the extreme grades would be more easily identifiable.

The AED blood level variability was more commonly assessed in the case of phenytoin and carbamazepine, but it is supposed that the lower variability would happen with long half-life drugs 
such as phenobarbital, higher in phenytoin and even higher in carbamazepine ${ }^{8,14,15}$. These results are also suggested in our study. However, our results do not show statistically different levels of variability according to phenobarbital and carbamazepine, suggesting homogeneity of the drug intake, in spite of different variability in the same patient according to the drug used in few cases.

Considering all these limitations, there is a natural tendency to perform more simple measures of patient adherence and its determinants, mainly in out-patients with chronic conditions such as epilepsy and to ensure adequate management in daily practice. Low cost and simple measures are more important in settings where literacy and socio-economic levels are low. In addition, the clinical approach has a major impact on this definition than blood drug measurement alone, and has to be linked to the clinical markers control for good therapeutic effectiveness and the self-reported adherence $e^{4,13,19}$. Consequently, there is also in the literature a tendency to show the reduction of overreliance on the AED blood evaluations. Better clinical management with adequate patient assessment is fundamental ${ }^{20,21}$. This reduction is also related to the better knowledge of AED pharmakocinetics principles such as their half-lives and steady-state periods ${ }^{12}$.

Acknowledgments - This project was in part funded by Rockefeller Foundation. We also acknowledge the collaboration of the staff of the Drug Monitoring Laboratory of the University Hospital and of the outpatient clinic at the Institute of Neurology, both of Universidade Federal do Rio de Janeiro. We are also grateful to Professor Brian Haynes for his comments and Dr. Fernando Machado Rodrigues for his help in the preparation of the manuscript.

\section{REFERENCES}

1. Gibberd FB, Dunne JF, Handley AJ, Hazleman BL. Supervision of epileptic patients taking phenytoin. BMJ 1970;1:147.149.

2. Eisler J, Mattson RH. Compliance in anticonvulsivant drug therapy. Epilepsia 1975;16:203.

3. Haynes B, Taylor DW, Sackett DL, Gibson ES, Bernholz CD, Mukherjee J. Can simple clinical measurements detect patient nonadherence. Hypertension 1980;2:757-764.

4. Fröscher W, Eichelbaum M, Gugler R, Hildenbrand G, Penin H. A prospective randomized trial on the effect of monitoring plasma anticonvulsants levels in epilepsy. J Neurol 1981;224:193-201.

5. Reynolds EH, Shorvon SD, Galbraith AW, Chadwick D, Dellaportas CI, Vydelingum L. Phenytoin monotherapy for epilepsy: a long.term prospective study, assisted by level monitoring, in previously untreated patients. Epilepsia 1981;22:475-488.

6. Bryant SG, Ereshefsky L. Determinants of compliance in epileptic outpatients. Drug Int Clin Pharm 1981;15:572-577.

7. Peterson GM, Mclean S, Millingen KS. Determinants of patient adherence with anticonvulsant therapy. Epilepsia 1982;23:607-713.

8. Takaki S, Kuroka WA, Aoyama T. Monitoring drug compliance in epileptic patients: assessing phenobarbital plasma levels. Ther Drug Mon 1985;7:87-91.

9. Stephenson BJ, Rowe BH, Haynes RB, Macharia WM, Leon G. Is this patient taking treatment as prescribed? JAMA 1993;269:2779-2781.

10. Gomes MM. Aderência à terapia anticomicial: II: Avaliação da aderência à medicação em epilepsia. Rev Bras Neurol 1987;23:151-153.

11. Chadwick DW. Overuse of monitoring of blood concentrations of antiepileptic drugs. BMJ 1987; 294:723.724.

12. Chadwick DW. Standard approach to antiepileptic drug treatment in the United Kingdom. Epilepsia 1994; 35(Suppl):S3-S10.

13. Gomes MM, Maia Fo HS, D’Andrea IO. Uso e valor da monitorização sérica de drogas antiepilépticas na prática clínicaestudo transversal. Braz J Epilep Clin Neuropharmacol 1996;2:117-120.

14. Leppik IE, Cloyd JC, Sawchuk RJ, Pepin SM. Compliance and variability of plasma phenytoin levels in epileptic patients. Ther Drug Mon 1979;1:475-483.

15. Leppik IE. Compliance in the treatment of epilepsy. In Wyllie E (ed). The treatment of epilepsy: principles and practice. 2.Ed. Baltimore: Wiliams \& Wilkins 1996;779-784.

16. Comission on Classification and Terminology of the International League Against Epilepsy. Proposal for revised clinical and electroencephalographic classification of epileptic seizures. Epilepsia 1981;22:489-501.

17. Rosner B. The coefficient of variatiion. In Fundamentals of biostatistics. 2.Ed. 1982:23-24.

18. Mattson RH. Antiepileptic drug monitoring: a reappraisal. Epilepsia 1995;36(Suppl5):S22-S29.

19. Comission on Antiepileptic Drugs, International League Against Epilepsy. Guidelines for therapeutic monitoring on antiepileptic drugs. Epilepsia 1993;34;582-587.

20. Mckee PIW, Larkin JG, Brodie AF, Percy-Robb IW, Brodie MJ. Five years of anticonvulsant monitoring on site at the epilepsy clinic. Ther Drug Mon 1993;15:83-90.

21. Schoenenberger RA, Tanasijevic MJ, Jha A, Bates DW. Appropriateness of antiepileptic drug level monitoring. JAMA $1995 ; 274: 1622-1626$. 